\title{
Within-country migration and obesity dynamics: analysis of 94,783 women from the Peruvian demographic and health
}

\section{surveys}

\author{
Hector Najera ${ }^{1}$, Shailen Nandy ${ }^{2^{*}}$ (D, Rodrigo M. Carrillo-Larco ${ }^{3}$ and J. Jaime Miranda ${ }^{3,4}$
}

\begin{abstract}
Background: Rural-to-urban migration is associated with increased obesity, yet it remains unknown whether this association exist, and to what extent, with other types of internal migration.

Methods: We conducted a secondary analysis of the Peruvian Demographic and Health Surveys (2005 to 2012) on data collected from women aged 15-49 years. Participants were classified as rural stayers, urban stayers, rural-tourban migrants, intra-rural migrants, intra-urban migrants, and urban-to-rural migrants. Marginal effects from a logit regression model were used to assess the probabilities of being and becoming obese given both the length of time in current place of residence and women's migration status.

Results: Analysis of cross-sectional survey data generated between 2005 and 2012. Data from 94,783 participants was analyzed. Intra-urban migrants and rural-to-urban migrants had the highest rates of obesity (21\% in 2012). A steady increase in obesity is observed across all migration statuses. Relative to rural non-migrants, participants exposed to urban environments had greater odds, two- to three-fold higher, of obesity. The intra-rural migrant group also shows higher odds relative to rural stayers ( $42 \%$ higher obesity odds). The length of exposure to urban settings shows a steady effect over time.

Conclusion: Both exposure to urban environments and migration are associated with higher odds of obesity. Expanding the characterization of within-country migration dynamics provides a better insight into the relationship between duration of exposure to urban settings and obesity.
\end{abstract}

Keywords: Migration, Obesity, Urbanization, Demographic and health surveys

\section{Background}

Over the last 40 years, there has been a significant increase in obesity, reflected by a high body mass index (BMI); between 1975 and 2014, global prevalence increased by 7.6 and $8.5 \%$ in men and women, respectively [1]. This pattern of increase however, is not uniform across countries or within countries, with different groups at greater or lesser risk both of becoming obese and also succumbing to associated health problems. A recent paper from Peru, using panel survey data on rural-to-urban migrants collected between 2007-08 and

\footnotetext{
* Correspondence: NandyS1@cardiff.ac.uk

${ }^{2}$ Cardiff University, Cardiff, UK

Full list of author information is available at the end of the article
}

2012-13 found that, compared to the rural group, rural-to-urban migrants and urban dwellers had an almost ten-fold greater risk of developing obesity [2]. Such discrepancies could be due to socio-economic differences, which determine exposure to known obesogenic risk factors such as sedentarism (low level of physical activity), limited access to healthy food choices among the worse-off [3], and stress $[4,5]$.

Although the risk factors for, and health consequences of, obesity are well known, how the probabilities of being obese vary according to different within-country internal migration profiles, and how these relationships behave over time, remains unknown in most low and middle-income countries (LMICs). Rapid urbanization is 
placing an undeniable strain on public resources in LMICs, and urban environments provide a range of challenges to newcomers from rural settings, particularly with regards to health and nutrition [6].

Collecting reliable longitudinal data in LMICs is expensive and difficult, and remains a challenge, particularly in settings where rural-to-urban migration is widespread, rapid and regular. Using repeated cross-sectional population-based surveys could be a pragmatic option to gain information both on migration profiles and health indicators. The aim of this paper is to assess the probabilities of being obese for different profiles of internal migration in Peru using the Peruvian Demographic and Health Surveys (DHS) from 2005 to 2012 [7]. In doing so we show how the use of cross-sectional household survey data can reflect patterns of obesity, and its relationship with migration, and could be used in many more LMICs.

\section{Methods}

\section{Study design}

Secondary-data analysis using repeated cross-section surveys from the Peruvian DHS conducted annually between 2005 and 2012. All datasets for the years 2005 to 2012 were pooled to increase power. The exposure variable (migration status, see below) is a nominal variable with small sample sizes for some categories and, therefore, a single year lacked sampling power to make a sensible inference.

\section{Study population}

Data on obesity and migration as well as residence status were obtained from women aged 15-49 years (Table 1). Excluded from analyses were visitors to the household and also the very small number of migrants from overseas who reported moving to rural areas.

\section{Variables \\ Primary exposure variable}

A derived variable to reflect migration status of respondents was created using information on their current place of residence, their childhood or previous place of residence, their current age, and the number of years lived in their current place of residence. This information was used to create six categories of resident status: (i) rural stayers (i.e., resident in the same rural area for all of their lives), (ii) urban stayers (i.e., resident in the same urban area for all of their lives), (iii) rural-to-urban migrants, (iv) intra-rural migrants (i.e., respondents who reported moving from one rural area to another), (v) intra-urban migrants (i.e., respondents who reported moving from one urban area to another), and (vi) urban-to-rural migrants (i.e., respondents who reported moving from an urban to a rural area).

\section{Outcome variable}

The outcome of interest was body mass index (BMI), calculated from height and weight measurements $\left(\mathrm{Kg} / \mathrm{m}^{2}\right)$.

Table 1 Summary statistics. Peru. 2005-2012, women aged 15-49

\begin{tabular}{|c|c|c|c|c|c|c|}
\hline & 2005 & 2007 & 2008 & 2009 & 2011 & 2012 \\
\hline Sample size & 5803 & 5932 & 14,957 & 22,969 & 21,761 & 23,361 \\
\hline Obesity (Prevalence \%) & 13 & 15 & 14 & 16 & 17 & 18 \\
\hline Age (Mean years) & 30 & 31 & 31 & 31 & 31 & 31 \\
\hline Education (Mean years of schooling) & 9 & 9 & 9 & 10 & 10 & 10 \\
\hline Wealth Index (Mean quintile) & 3 & 4 & 4 & 3 & 3 & 3 \\
\hline Duration in place of residence & 22 & 22 & 22 & 22 & 21 & 22 \\
\hline \multicolumn{7}{|l|}{ (Mean years) } \\
\hline Migration status & \multicolumn{6}{|c|}{$\%$ (Column) } \\
\hline Urban stayers & 41 & 39 & 42 & 43 & 40 & 41 \\
\hline Intra-urban migrants & 22 & 23 & 23 & 24 & 25 & 24 \\
\hline Rural stayers & 20 & 18 & 17 & 15 & 14 & 13 \\
\hline Rural-to-Urban migrants & 6 & 10 & 9 & 8 & 10 & 10 \\
\hline Intra-rural migrants & 5 & 6 & 5 & 5 & 6 & 6 \\
\hline Urban-to-Rural migrants & 7 & 5 & 5 & 5 & 5 & 6 \\
\hline Ethnicity (language) & \multicolumn{6}{|c|}{$\%$ (Column) } \\
\hline Spanish speaker & 96 & 95 & 96 & 96 & 96 & 95 \\
\hline Quechua & 2 & 5 & 4 & 3 & 4 & 4 \\
\hline Aymara & 1 & 0 & 0 & 1 & 0 & 1 \\
\hline Other & 0 & 0 & 0 & 0 & 0 & 0 \\
\hline
\end{tabular}

Standard deviations are almost constant across years for the continuous variables: 
Respondents with a BMI of $30 \mathrm{Kg} / \mathrm{m}^{2}$ or more were classified as obese [8].

\section{Auxiliary variables}

Auxiliary variables included household wealth index, based on information on ownership of assorted assets and access to services, such as water source and form of sanitation [9]; level of education (years of education); ethnicity (language spoken at home), and length of time in current place of residence (in years). The participant's age is presented in years. We also controlled for geographical region and altitude of respondent's current place of residence [10]. These two variables were used as potential confounders in the analysis.

\section{Statistical analysis}

For descriptive purposes, numeric variables were summarized with means, and categorical variable were presented as percentages along with 95\% Confident Intervals $(95 \% \mathrm{CI})$. A multivariable logit model was utilized to analyze the relationship between obesity and the exposure variable. Marginal effects (Adjusted Predictions at the Means) were computed from the logit model to obtain the predicted probabilities of being obese, given the length of current place of residence, with rural stayers, i.e. respondents who reported living in a rural location for all their lives and never migrating, set as the reference group. Survey weights and year of the survey were utilized to adjust the estimates and capture between-survey differences. The models were fitted using the pooled dataset 2005-2012. To explore whether the migration groups changed in terms of socioeconomic profiles over time, we plotted their mean asset index scores for the years 2005 to 2012 without observing major differences.

\section{Results}

Sample characteristics

Data from 94,783 women was analyzed and sample size ranged from 5803 to 23,361 participants in 2005 and 2012, respectively (Table 1). Average age of respondents at the time of each survey was 30 years, and the mean duration in their place of residence at the time of the interview was 22 years. There were two apparent changes in the composition of the sample, with the share of rural stayers falling from $20 \%$ in 2005 to $13 \%$ in 2012; in contrast, the share of rural-to-urban migrants increased from 6 to $10 \%$ over the same period. Overall obesity prevalence among women increased from $13 \%$ [95\% CI 12-14\%] in 2005 to $18 \%$ [95\% CI 17-19\%] in 2012. All other variables remained stable over the seven-year period (Table 1).

\section{Migration and obesity}

The prevalence of obesity by migration status (Table 2) shows two clear patterns. First, the prevalence of obesity has substantially increased in all study groups between 2005 and 2012, except for urban-to-rural migrants whose confidence intervals overlap, meaning differences in means are not statistically significant. The overall increases in obesity prevalence ranged between $20 \%$ and $46 \%$ with respect to the 2005 prevalence estimates, but there was almost a doubling in the prevalence of obesity among intra-rural migrants. On its own this finding would be a concern, but it is mitigated somewhat by the fact that obesity amongst this group is relatively low (13\% in 2012). Second, there is a gradient in the prevalence estimates: rural stayers have the lowest rates of obesity, followed by intra-rural migrants, urban-to-rural migrants, urban-stayers, intra-urban migrants, and rural-to-urban migrants; this gradient was observed in all study years.

Table 2 Obesity prevalence rate (\%, and $95 \mathrm{Cl}$ ) by migration status

\begin{tabular}{|c|c|c|c|c|c|c|}
\hline Year & Rural stayers & Intra-rural migrants & Urban to rural migrants & Urban stayers & Intra-urban migrants & Rural to urban migrants \\
\hline \multirow[t]{2}{*}{2005} & 6.7 & 6.6 & 11.8 & 13.7 & 17.0 & 15.2 \\
\hline & {$[5.2-8.3]$} & [3. 5-9.8] & {$[8.45-15.2]$} & {$[12.2-15.1]$} & {$[14.7-19.1]$} & [10.9-19.3] \\
\hline \multirow[t]{2}{*}{2007} & 7.6 & 8.6 & 10.2 & 15.0 & 20.8 & 21.6 \\
\hline & [6.0-9.2] & {$[5.6-11.5]$} & {$[6.67-13.6]$} & {$[13.5-16.3]$} & {$[18.6-22.9]$} & [18.2-24.9] \\
\hline \multirow[t]{2}{*}{2008} & 7.7 & 11.8 & 11.6 & 13.9 & 19.0 & 20.4 \\
\hline & [6.6-8.9] & {$[9.4-14.1]$} & {$[9.18-14.0]$} & {$[13.0-14.7]$} & {$[17.6-20.4]$} & {$[18.0-22.6]$} \\
\hline \multirow[t]{2}{*}{2009} & 8.5 & 11.3 & 14.5 & 16.5 & 18.6 & 20.1 \\
\hline & {$[7.6-9.5]$} & {$[9.5-13.0]$} & {$[12.4-16.5]$} & {$[15.7-17.2]$} & {$[17.5-19.6]$} & {$[18.2-21.9]$} \\
\hline \multirow[t]{2}{*}{2011} & 9.3 & 12.8 & 14.3 & 17.5 & 18.7 & 25.1 \\
\hline & {$[8.3-10.4]$} & [11.0-14.6] & {$[12.2-16.4]$} & [16.7-18.3] & {$[17.6-19.7]$} & {$[23.2-26.9]$} \\
\hline \multirow[t]{2}{*}{2012} & 9.8 & 13.0 & 15.3 & 18.8 & 20.5 & 21.0 \\
\hline & {$[8.7-10.8]$} & {$[11.2-14.7]$} & [13.2-17.2] & [18.0-19.6] & {$[19.4-21.5]$} & {$[19.3-22.7]$} \\
\hline 2012 vs 2005 increase $^{a}$ & $46.3 \%$ & $97 \%$ & - & $37.2 \%$ & $20.6 \%$ & $38.2 \%$ \\
\hline
\end{tabular}

${ }^{2}$ These increases are calculated with respect to 2005 values. Figures not calculated for urban-to-rural migrants because confidence intervals for 2012 and 2005 overlap 
The multivariable logit model (Table 3) indicate that, relative to rural stayers, all other groups had higher odds of being obese; these odds were almost three times higher in the two groups migrating to urban areas (i.e. intra-urban, and rural to urban migrants). There is also a positive relationship between years lived in place of residence and the probabilities of being obese. Relative to year 2005, the odds of being obese increased in most recent years, being up to $46 \%$ higher in 2012. Belonging to a non-Spanish speaking community (i.e. Quechua and other indigenous language speakers) had a protective effect, with around half the risk of being obese in all language groups except for Aymara speakers.

\section{Marginal effects}

Figure 1 and Fig. 2 show the relationship between migration status and the likelihood of being obese, by years lived in place of residence and adjusting by the mean

Table 3 Multivariable logit model for obesity

\begin{tabular}{|c|c|c|}
\hline & \multicolumn{2}{|l|}{ Obesity } \\
\hline & Odds ratio & $95 \% \mathrm{Cl}$ \\
\hline \multicolumn{3}{|l|}{ Migration status } \\
\hline Rural stayers & Reference & \\
\hline Intra-rural migrants & $1.42^{* * *}$ & {$[1.22-1.65]$} \\
\hline Urban to rural migrants & $2.22^{* * *}$ & {$[1.91-2.58]$} \\
\hline Urban stayers & $2.54^{* * *}$ & {$[2.28-2.83]$} \\
\hline Intra-urban migrants & $2.90^{* * *}$ & {$[2.50-3.36]$} \\
\hline Rural to urban migrants & $2.84^{* * *}$ & {$[2.45-3.29]$} \\
\hline \multicolumn{3}{|l|}{ Year } \\
\hline 2005 & Reference & \\
\hline 2007 & $1.17^{*}$ & {$[1.01-1.38]$} \\
\hline 2008 & 1.07 & {$[0.95-1.23]$} \\
\hline 2009 & $1.27^{* * *}$ & [1.13-1.44] \\
\hline 2011 & $1.46^{* * *}$ & [1.25-1.59] \\
\hline 2012 & $1.46^{* * *}$ & {$[1.29-1.63]$} \\
\hline \multicolumn{3}{|l|}{ Ethnicity (language) } \\
\hline Spanish speaker & Reference & \\
\hline Quechua & $0.48^{* * *}$ & {$[0.43-0.54]$} \\
\hline Aymara & 0.82 & {$[0.63-1.06]$} \\
\hline Other indigenous & $0.26^{* * *}$ & {$[0.14-0.49]$} \\
\hline Other (foreign) & $0.15^{*}$ & {$[0.03-0.80]$} \\
\hline Constant & $0.01^{* * *}$ & {$[0.01-0.01]$} \\
\hline \multicolumn{3}{|l|}{ Sociodemographic variables } \\
\hline Age in years & $1.06^{* * *}$ & {$[1.06-1.07]$} \\
\hline Wealth index & $1.09 * * *$ & {$[1.06-1.12]$} \\
\hline Education (in years) & $0.95^{* * *}$ & {$[0.94-0.96]$} \\
\hline Years lived in place of residence & $1.01^{* * *}$ & [1.01-1.02] \\
\hline
\end{tabular}

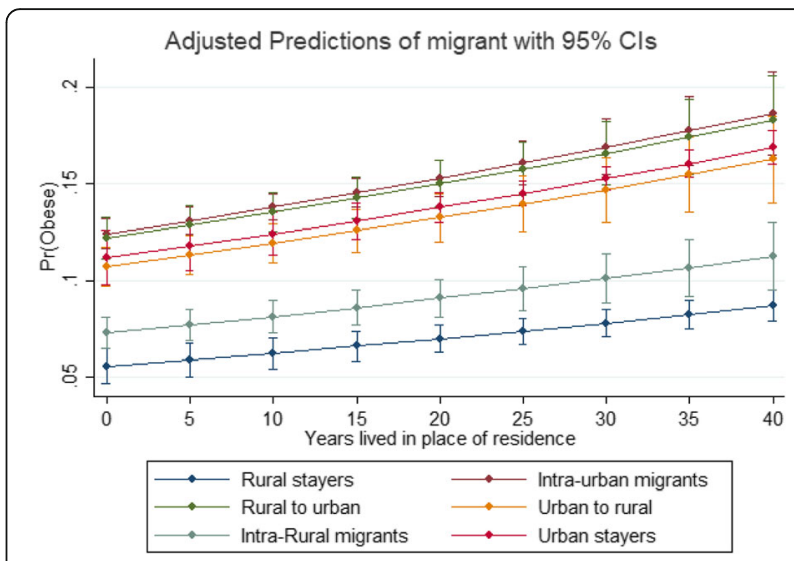

Fig. 1 Marginal effects (predicted probabilities of being obese). All migration categories

values of the other variables (i.e. age, mean number of years of education, ethno-linguistic group, and region and altitude of residence). Figure 1 shows the predicted probabilities (obtained from the model) of being obese for all internal migration categories according to years lived in the place of residence. The plot suggests that migration to urban sites might have a higher effect on obesity than migration to rural areas. Although the gradient looks similar, the change overtime is significantly different across groups. For example, relative to rural stayers, rural-to-urban migrants are slightly more likely to become obese overtime (1\% per year). Figure 2 compares these estimates for rural stayers and rural-to-urban migrants, with the latter showing greater obesity odds regardless of time lived in place of residence. Overall, the plots suggest little differences when accounting the years lived in place of residence. However, as the lines are not parallel, this indicates there is an effect over-time: the slightly steeper gradient for urban-to-rural migrants suggests a faster rate of becoming obese, compared to the

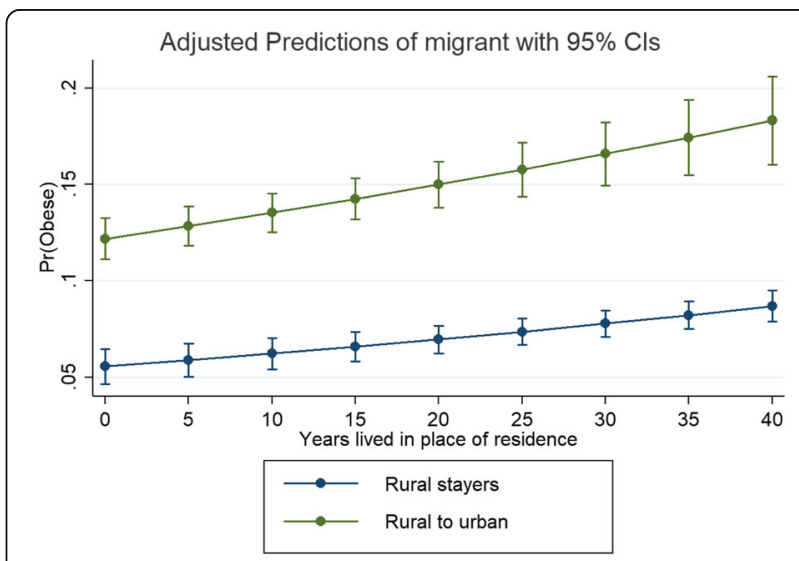

Fig. 2 Marginal effects (predicted probabilities of being obese). Rural to urban migrants and rural stayers 
other groups. This confirms the findings of work done in Peru using panel data [2].

\section{Discussion}

Most studies have characterized BMI levels and obesity rates in national aggregates, stratifying results by rural and urban settings. Yet, the nature of demographic change in most LMICs today means population distributions are changing rapidly as a result of ongoing internal migration processes. In this study we aimed to characterize obesity rates by expanding into a more detailed profiling of populations and benefiting from existing extensive data of internal migration in Peru. Over the 7-year study period we observed an increase in the prevalence of obesity in all study groups, with the intra-urban migrants and rural-to-urban migrants having the highest rates of obesity (around 21\% in 2012); those remaining in rural had the lowest rates (10\% in 2012). The largest increase in obesity rates over the period was observed among the intra-rural migrants, from $6.6 \%$ in 2005 to $13 \%$ in 2012 . We found that, relative to rural stayers, all those who exposed to urban environments, including urban-to-rural migrants, had from two- to three-fold greater odds of obesity. These raised probabilities are also observed in the intra-rural migrant group, which had $42 \%$ higher obesity odds relative to rural non-migrants. Taken together, these findings indicate that both exposure to urban environments and migration are associated with higher odds of obesity, and our study advances the characterization of the association of migration-obesity profiles.

Given the rapid pace of urbanization in most LMICs, driven largely by rural to urban migration, these findings help illustrate the impact of urbanization, and the exposure to urban settings more precisely, is not uniform across groups; important changes are occurring across the spectrum of migration profiles: while migrants to an urban setting have much higher rates of obesity, the increase in the magnitude of obesity prevalence is considerably greater among intra-rural migrants in Peru. In general, any pattern of migration, i.e. migration into an urban or into a rural area, is associated with obesity.

We have previously shown that exposure to urban environments is linked to higher odds of obesity, with a clear relationship with duration of residence in urban settings. This supports comparable findings with other studies focused on rural-to-urban only migrants in Peru $[2,11]$, and in other LMICs undergoing internal migration [12]. In this study, we were able to also observe a relationship, albeit smaller, in the same direction of increased obesity with rural migration. This means that any migration, irrespective of the host environment, is associated with increased odds of obesity. Although this appears counter-intuitive, particularly for intra-rural migrants, as most of the literature signals that exposure to rural areas exert a protective factor for obesity. Our study adds further granularity into this human-environment exposure in that migration per se introduces changes, some of them behavioral ones, that override the protective factor of being exposed to a rural area. Hence, internal migration per se, and not only rural-to-urban migration, becomes a risk factor for obesity.

A recent population-based study in India, also using cross-sectional data, found higher obesity odds among intra-urban and rural-to-urban women migrants, though the results for men were not conclusive [13]. That said, in contrast to our results, Varadharajan et al. found that urban-to-rural migration in women was a protective factor against obesity [13]. These differences could be due to the fact that India is less urbanized than Peru [14] and significantly poorer [15], and thus migrants in Peru are more exposed to the unhealthy lifestyles associated with prolonged exposure to urban living. Our results, including prospective studies [2], could signal an alert for a developing obesity epidemiological scenario in India and other LMICs which while still less urbanized than Peru [14], are indeed undergoing urbanization.

Our results could be explained by differences in socioeconomic status amongst migration groups. It is often argued that migration towards urban sites is motivated and facilitated by better socio-economic status i.e. people migrate to look for work or better living conditions in urban areas, but also that those able to migrate are relatively better off $[16,17]$. In fact, a previous cross-sectional study with Peruvian rural-to-urban migrants found that lower socio-economic status and the conditions of poverty were associated with lower odds of obesity [18]. In a way, this reflects the fact that obesogenic drivers closely follow lifestyles associated with, or made possible by, a higher socio-economic status. From a pragmatic point of view, our findings support calls to promote obesity-prevention strategies in rural areas and in all those sites undergoing economic improvement, to stave off potential obesity epidemics and the health problems and costs this entails [19].

Over the last decades, Peruvians have moved from rural to urban areas seeking of better opportunities: improved education, access to services and housing [20, 21]. However, this is not always possible and rural-to-urban migrants usually move to the outskirts of Lima (capital city) and build their own houses, lacking access to basic services (e.g., potable water). Overall, rural-to-urban migrants have been characterized as: young rural women, mostly indigenous, illiterate, with dearth of knowledge about living in the city, with poor household background, and mostly working in household and agriculture [22]. Therefore, what could have driven our results 
is probably the exposure to urbanization, either because of rural-to-urban migration or due to the increasing urbanization of rural areas, rather than the migrants having different characteristics than their predecessors.

Our study has found that different migration profiles are associated with greater or lesser odds of being and becoming obese. Increases in obesity rates at the population level reflect shifting BMI levels, where increases of up to $5 \mathrm{Kg} / \mathrm{m}^{2}$ units have been linked to a three-time greater risk of developing diabetes [23]. Hence, if we were to apply these assumptions to a LMIC like Peru, our analysis would support both the understanding and forecasting of the epidemic of diabetes, a costly cardio-metabolic risk factor associated to loss of productivity and early mortality [24]. Understanding both urban and rural settings merit attention and is important. Whilst greater focus has been placed on public health and nutrition in urban settings, no doubt due to the greater perceived burden, a significant proportion of the population are still based in rural areas; our findings could well inform preventive strategies and health messages which could be applied to tackle growing obesity in both rural and urban settings. Also important is developing public health messages to parents and grandparents to stave off obesity in young children, given the rising prevalence of obesity across the world [19].

Our study benefitted from a large sample size from a population-based survey of Peruvian women, with almost annual data from 2005 to 2012 and with a dynamic within-country migration profile. The use of the Peru DHS is an asset because it allows for an examination of the geographic and sociodemographic differences in health outcomes according to internal migration profiles. We acknowledge the limitations of this study. We were unable to control the regression models for the initial conditions of the population, particularly participants' BMI prior to migration. However, our aim was not to assess the longitudinal trajectory of individual BMI or to assess changes over time for a given group. We aimed, instead, to assess the effect of internal migration and to see if such an effect varied over a period of time. Also, our regression models did not account for other overweight determinants, such as diet or physical activity, because these variables were not available. Future studies on trajectories of weight should include these variables, particularly when assessing people changing from rural to urban sites, or vice versa. For some migration categories, i.e., urban-to-rural or intra-rural migrants, there were small numbers in the sample (Table 1), and this could have compromised the statistical power of the regression analysis. In addition, other co-variables also had small sample size in some categories (e.g., ethnicity). Thus, results for these small groups deserve a cautious interpretation. Nonetheless, this should not be regarded as a limitation, because our results are robust for rural-to-urban migration, which happens to be the most frequent migration. Finally, the large sample size available only included adult women aged $15-49$ years in the study, given there were no similar data on men for the same time period. Therefore, our results partially inform of the overall scenario in Peru, without including men or older women.

\section{Conclusion}

In conclusion, urban exposure is associated with higher probability of being obese. Although rural exposure seemed to be a protector factor, the effect among urban-to-rural migrants diminished with duration in place of residence. The increasing odds of obesity across all groups in Peru forecast an alarming scenario given a high $\mathrm{BMI}$ is a risk factor for cardio-metabolic conditions. The fact that the rate of increase of obesity is highest for rural-to-urban migrants should be a concern for public health, given rural areas constitutes the main reservoir of potential migrants across LMICs. Obesity prevention strategies could take some lessons from rural areas, as these settings seem to protect against high BMI, but given that obesity prevalence rates in rural areas are also rising rapidly suggests a need to monitor the nutrition and demographic dynamics in both urban and rural settings.

\section{Abbreviations}

95\%Cl: 95\% Confidence Intervals; BMI: Body Mass Index; DHS: Demographic and health survey; LMIC: Low- and middle-income countries

\section{Acknowledgements}

We thank the DHS for making such useful data freely-available to researchers.

\section{Funding}

HN and SN are funded in part by a UK ESRC-GCRF SDAl grant, number ES/ P00346/X/1. RMCL has received support as a trainee from the Inter-American Institute for Global Change Research (IAI CRN3036), and the National Heart, Lung and Blood Institute (contract HHSN268200900033C). JJM acknowledges receiving additional support from the DFID/MRC/Wellcome Global Health Trials (MR/M007405/1), Fogarty International Center (R21TW009982), International Development Research Center Canada (106887, 108167), InterAmerican Institute for Global Change Research (IAI CRN3036), Medical Research Council (MR/P008984/1), National Heart, Lung and Blood Institute (HHSN268200900033C, 5U01HL114180, 1UM1HL134590), National Institute of Mental Health (1U19MH098780), Swiss National Science Foundation (40P740-160366), Wellcome Trust (205177/Z/16/Z), and the World Diabetes Foundation (WDF15-1224). None of the funding bodies identified had any role in the design of the study, in data collection, or in analysis, interpretation or writing the manuscript.

\section{Availability of data and materials}

This paper uses data from the Demographic and Health Surveys (DHS) for Peru (2005-2012). See: https://dhsprogram.com/Where-We-Work/CountryMain.cfm?ctry_id $=33 \& c=$ Peru\&Country $=$ Peru\& $c n=\& r=6$

\section{Authors' contributions}

JJM and SN designed the study; RMCL, HN, SN and JJM contributed to the analysis plan. HN and RMCL conducted the statistical analysis. RMCL, SN and 
HN drafted the manuscript. All authors contributed scientifically to the manuscript, with particular emphasis on results interpretation. All authors read and approved the final version before submission.

\section{Ethics approval and consent to participate}

No personal information was used in this analysis, and no attempts were made to identify subjects surveyed. All data used in this study was anonymous. No human subjects were included in the study; therefore, we did not request approval from any ethics committee and there was no need for informed consents.

\section{Consent for publication}

NA

\section{Competing interests}

The authors declare that they have no competing interests.

\section{Publisher's Note}

Springer Nature remains neutral with regard to jurisdictional claims in published maps and institutional affiliations.

\section{Author details}

${ }^{1}$ University of Bristol, Bristol, UK. ${ }^{2}$ Cardiff University, Cardiff, UK. ${ }^{3}$ CRONICAS Centre of Excellence in Chronic Diseases, Universidad Peruana Cayetano Heredia, Lima, Peru. "School of Medicine "Alberto Hurtado", Universidad Peruana Cayetano Heredia, Lima, Peru.

\section{Received: 20 February 2018 Accepted: 22 February 2019}

\section{Published online: 04 March 2019}

\section{References}

1. Soose RJ, Woodson BT, Gillespie MB, Maurer JT, de Vries N, Steward DL, Strohl KP, Baskin JZ, Padhya TA, Badr MS, et al. Upper airway stimulation for obstructive sleep apnea: self-reported outcomes at 24 months. J. Clin. Sleep Med. 2016:12:43-8

2. Carrillo-Larco RM, Bernabe-Ortiz A, Pillay TD, Gilman RH, Sanchez JF, Poterico JA, Quispe R, Smeeth L, Miranda JJ. Obesity risk in rural, urban and rural-to-urban migrants: prospective results of the Peru migrant study. Int J Obes. 2015. https://doi.org/10.1038/ijo.2015.140.

3. Ebrahim S, Kinra S, Bowen L, Andersen E, Ben-Shlomo Y, Lyngdoh T, Ramakrishnan L, Ahuja RC, Joshi P, Das SM, et al. The effect of rural-to-urban migration on obesity and diabetes in India: a cross-sectional study. PLoS Med. 2010;7:e1000268. https://doi.org/10.1371/journal.pmed.1000268.

4. Delavari M, Sønderlund AL, Swinburn B, Mellor D, Renzaho A. Acculturation and obesity among migrant populations in high income countries - a systematic review. BMC Public Health. 2013;13:458. https://doi.org/10.1186/ 1471-2458-13-458.

5. Jackson SE, Kirschbaum C, Steptoe A. Hair cortisol and adiposity in a population-based sample of 2,527 men and women aged 54 to 87 years. Obesity. 2017;25:539-44. https://doi.org/10.1002/oby.21733.

6. IOM. Internal migration and development: a global perspective. Geneva: International Organization for Migration; 2005.

7. Corsi DJ, Neuman M, Finlay JE, Subramanian S. Demographic and health surveys: a profile. Int J Epidemiol. 2012;41:1602-13. https://doi.org/10.1093/ ije/dys184.

8. WHO. Physical status: the use and interpretation of anthropometry. In: Report of a WHO expert committee: WHO technical report series 854. Geneva: World Health Organization; 1995.

9. Rutstein, S. O., Johnson, K. 2004 The D.H.S. wealth index. Calverton, Maryland: ORC Macro.

10. Woolcott OO, Gutierrez C, Castillo OA, Elashoff RM, Stefanovski D, Bergman RN. Inverse association between altitude and obesity: a prevalence study among Andean and low-altitude adult individuals of Peru. Obesity (Silver Spring, Md.). 2016;24(10.1002/oby.21401):929-37.

11. Miranda JJ, Gilman RH, Smeeth L. Differences in cardiovascular risk factors in rural, urban and rural-to-urban migrants in Peru. Heart. 2011;97:787-96. https://doi.org/10.1136/hrt.2010.218537

12. Hernández AV, Pasupuleti V, Deshpande A, Bernabé-Ortiz A, Miranda JJ. Effect of rural-to-urban within-country migration on cardiovascular risk factors in low- and middle-income countries: a systematic review. Heart. 2012;98:185-94. https://doi.org/10.1136/heartjnl-2011-300599.
13. Varadharajan KS, Thomas T, Rajaraman D, Kurpad AV, Vaz M. Overweight and obesity among internal migrants in India. Asia Pac J Clin Nutr. 2013;22: 416-25. https://doi.org/10.6133/apjcn.2013.22.3.14.

14. Sumner A. Year economic and non-economic well-being: a review of progress on the meaning and measurement of poverty. Inequality, poverty and human well-being; 2003. Helsinki: UNU-WIDER; 2003.

15. World Bank. 2012 World Development Report on Gender Equality and Development. Washington D.C.: World Bank; 2012.

16. Harris JR, Todaro MP. Migration, unemployment and development: a twosector analysis. Am Econ Rev. 1970;60:126-42.

17. Awumbila M, Owusu G, Teye JK. Can rural-urban migration into slums reduce poverty? In: Evidence from Ghana Migrating Out of Poverty Working Paper, vol. 13; 2014. p. 1-41.

18. Hilmers A, Bernabe-Ortiz A, Gilman RH, McDermott AY, Smeeth L, Miranda J. Rural-to-urban migration: socioeconomic status but not acculturation was associated with overweight/obesity risk. J Immigr Minor Health. 2016; 18:644-51. https://doi.org/10.1007/s10903-015-0234-9.

19. The GBD Obesity Collaborators. 2017 Health Effects of Overweight and Obesity in 195 Countries over 25 Years. New England Journal of Medicine. June 12th, (https://doi.org/10.1056/NEJMoa1614362).

20. International Organization for Migration (IOM). Perfil Migratorio del Peru 2012. Lima: IOM; 2012

21. Yamada, G. 2010 Yamada, Gustavo, growth, employment and internal migration: Peru, 2003-2007 (march 1, 2010). SSRN. Available at SSRN: https://ssrn.com/abstract=1590603. Accessed 1 Mar 2010.

22. Naranjo Morales AG. The Peruvian Migration Phenomenon. Lima: Centro de Asesoría Laboral del Perú; 2007.

23. Bernabe-Ortiz A, Carrillo-Larco RM, Gilman RH, Miele CH, Checkley W, Wells JC, Smeeth L, Miranda JJ. Geographical variation in the progression of type 2 diabetes in Peru: the CRONICAS cohort study. Diabetes Res Clin Pract. 2016:121:135-45. https://doi.org/10.1016/j.diabres.2016.09.007.

24. Morgan MSC, Antonelli JA, Lotan Y, Shakir N, Kavoussi N, Cohen A, Pearle MS. Use of an electronic medical record to assess patient-reported morbidity following Ureteroscopy. J Endourol. 2016;30(Suppl 1):S46-51.

\section{Ready to submit your research? Choose BMC and benefit from:}

- fast, convenient online submission

- thorough peer review by experienced researchers in your field

- rapid publication on acceptance

- support for research data, including large and complex data types

- gold Open Access which fosters wider collaboration and increased citations

- maximum visibility for your research: over $100 \mathrm{M}$ website views per year

At $\mathrm{BMC}$, research is always in progress.

Learn more biomedcentral.com/submissions 